\title{
Desvios de imagens ${ }^{1}$
}

\section{Anita Leandro}

\section{Resumo}

Desviar as imagens já existentes de sua função original e utilizá-las em novos contextos, de forma a potencializar 0 alcance político da montagem e a transformar o cinema num lugar de troca de experiências: era esse o projeto de Guy Debord, retomado, hoje, sob novas bases, por cineastas que trabalham com imagens de arquivo. Através dos filmes e textos de Debord, esse artigo analisa a técnica do desvio e avalia a atualidade da proposta do cineasta situacionista, estabelecendo vínculos entre seu método de montagem e o de Eduardo Coutinho, em Um dia na vida.

\section{Palavras-chave}

Debord. Coutinho. Desvio.

Anita Leandro I anita@leandro@eco.ufrj.br Doutoura em cinema pela Université Sorbonne Nouvelle - Paris 3. Professora adjunta da Universidade Federal do Rio de Janeiro (UFRJ).

\section{Estratégias}

Inicialmente ligado ao Movimento Letrista, que, no início dos anos 1950, quis restaurar a força primitiva da linguagem, atribuindo à letra um sentido independente da palavra, vinculado à matéria sonora, Guy Debord participa, em 1957, da organização do Situacionismo, movimento artístico e político europeu, formado por dissidentes do letrismo e pintores do Grupo Cobra, que propunham o retorno à espontaneidade criadora e à pesquisa experimental de valores populares e coletivos. Debord foi uma figura central do movimento situacionista, dissolvido em 1972. Em 1984, em reação ao misterioso assassinato de seu amigo, editor, produtor, distribuidor e mecenas Gérard Lebovici, ele proibiu a projeção de todos os seus filmes, enquanto vivesse. Esse ato extremo, bastante coerente, pois vindo de alguém que tinha como projeto político, justamente, a ultrapassagem da arte, em direção a outros modos de compartilhamento da experiência estética, privou-nos, durante mais de duas décadas, de um encontro com os filmes de Debord. Mas foi assim que sua obra ficou, de alguma forma, protegida de 
apropriação por parte da "sociedade espectacular" que ele se esforçou em definir (DEBORD, 1992). Lugar de redução da experiência viva à imagem dessa experiência, 0 espetáculo transforma em mercadoria consumível até mesmo a arte, que a partir do barroco, começa a desconectar-se cada vez mais da linguagem comum e da vida. A atitude de Debord é uma forma de enfrentar esse problema político, atribuindo aos seus filmes um outro destino histórico. Retrospectivamente, a interdição de seus filmes pode ser entendida como um gesto de montagem: ao interromper a fruição de sua obra no presente, ele transformou-a em arquivo, desafiando o espectador de hoje a retomar esse projeto a partir do ponto em que ele foi interrompido.

Debord suicidou-se em 1994 e no final de 2005 sua obra foi editada em DVD e distribuída novamente em salas de cinema. Seus filmes ressurgem como um bumerangue na aurora do século XXI e 0 apelo distante do cinema situacionista encontra, hoje, ressonância nas práticas mais audaciosas de remontagem das imagens do espetáculo, como Um dia na vida (2010), por exemplo, filme recente de Eduardo Coutinho. A atualidade do projeto de
Debord desconcerta até os críticos mais reticentes de sua obra. Não somente a mais valia e 0 controle do visível encontram-se, atualmente, no centro de todos os debates sobre a relação entre imagem e política, mas também a própria montagem, motor do projeto estético debordiano, ressurge no espaço contemporâneo como, talvez, o último dispositivo ainda capaz de reunir aquilo que 0 espetáculo separou. Mas, acima de tudo, o projeto político de Debord nos atinge em cheio devido à eficácia de sua técnica de composição, que substitui a filmagem pelo desvio de função e de sentido de imagens já existentes. ${ }^{2}$

Os sete documentários que Debord realizou entre 1952 e 1994 são um questionamento profundo de ordem ética sobre a retomada das imagens que povoam nosso cotidiano. Construídos à base de arquivos, reunindo imagens de todo tipo - noticiários cinematográficos e de televisão, trechos de filmes de ficção hollywoodianos e filmes de propaganda soviéticos, publicidades, fotografias de revistas de moda, mas também dos próprios amigos do cineasta - os filmes de Debord revigoraram a prática da montagem. Seu método aproxima acontecimentos distantes uns

Esse artigo está relacionado ao projeto de pesquisa Palavra, arquivo e memória, apoiado pelo CNPq. Ele desenvolve questões originalmente abordadas em Politiques du montage chez Guy Debord (LEANDR0, 2006) e apresentadas ao Grupo de Trabalho Estudos de cinema, fotografia e audiovisual do XXI Encontro da Compós, de 2012.

A montagem de arquivos de Harun Farocki ou de Yervant Gianikian e Angela Ricci Lucci, por exemplo, que tem despertado 0 interesse de historiadores da arte e de teóricos do cinema, retoma, sob vários aspectos, o projeto debordiano de desvio das imagens. Em Turismo vândalo, de Gianikian e Ricci Lucci (2001), a retomada de imagens amadoras de turistas ingleses dos anos 1920, na Índia, traz à tona o discurso classista e o racismo velado do colonizador. Um procedimento similar é encontrado em Videogramas de uma revolução, de Harun Farocki e Andrei Ujica (1991-1992), que tira do contexto midiático as imagens da queda de Ceausescu, transmitidas pela televisão romena, confrontando-as, na montagem, a imagens de cinegrafistas amadores. 
dos outros, trazendo à tona aspectos recalcados da vida. Para Debord, a ativação da memória potencial das imagens pela montagem era uma forma de engajamento do cinema no tempo histórico. A recusa em acrescentar novas imagens ao mundo do espetáculo e o desvio de função de imagens já filmadas transformam a montagem num ato cinematográfico eminentemente político, pois capaz de reunir o que foi separado, de desmontar discursos e de remontar as imagens do espetáculo de outra maneira, para, finalmente, devolvê-las, desreificadas, ao espectador, como matéria-prima destinada a sua atividade criadora. Para Debord, talvez mais do que para Godard ou, até mesmo, Marker, o cinema foi, obsessivamente, uma questão de montagem. E a montagem, uma estratégia política de deslocamento das imagens, pois só ela permite tirar as imagens do lugar onde se encontram, confiscadas, e trazê-las de volta à vida, ao espaço da confrontação.

\section{Esquecimento}

Quando, no cinema, há interesse pela retomada de imagens já existentes, a prática vem, geralmente, acompanhada por uma espécie de sacralização do passado, enquanto passado. A reivindicação do ato de memória é formulada do ponto de vista de um saber histórico pré-estabelecido, que subtrai da imagem assim atualizada seu caráter material, documental. Ela não é abordada como matéria sensível e singular, como se faz com testemunhas vivas, lugares de memória ou monumentos, mas como ilustração de discursos, de teses, sejam elas de direita ou de esquerda. A imagem é, de antemão, apresentada pela montagem como mito, como monumento, sem que seu estatuto de documento seja, no entanto, reconhecido. 0 argumento da memória é, geralmente, 0 álibi desse tipo de pilhagem, que Debord condena. Por isso, quando ele se apropria das imagens da televisão ou do próprio cinema, não é o dever de memória que é evocado num primeiro momento, mas, paradoxalemente, 0 direito a 0 esquecimento. No início de um de seus primeiros filmes, Sur le passage de quelques personnes à travers une assez courte unité de temps Sobre a passagem de algumas pessoas por uma curta unidade de tempo (1959) -, ele diz, num tom nostálgico, que o esquecimento era a paixão dominante dos situacionistas.

0 esquecimento como paixão: ideia contraditória, vinda de alguém que aos 29 anos de idade publicou um livro intitulado, justamente, Mémoires (DEBORD; JORN, 1958), e que, ao longo de sua vida, não parou de agregar pessoas, cultivando amizades e criando pequenos atos cotidianos de compartilhamento de experiências, por ele chamados pelo modesto termo de "situações" (DEB0RD, 2000). A contradição é apenas aparente. 0 esquecimento, em seus filmes, é o contraponto da lembrança, a condição para inventar uma memória, num presente dela desprovido. A montagem de Debord é um apagamento sistemático dos discursos préestabelecidos que as imagens armazenam: em corte seco, sem nenhum efeito, sua montagem 
mostra a separação enquanto tal e impede que 0 sentido de uma imagem se prolongue na imagem seguinte por meio de fusões ou qualquer outro tipo de encadeamento que venha suavizar a troca de planos. Seu texto, em off, omnipresente, lido sempre por ele mesmo, na primeira pessoa, age como uma guilhotina sobre a pseudo continuidade das grandes narrativas midiáticas e midiatizadas, portadoras de uma falsa memória.

É preciso refutar o próprio cinema, esvaziá-lo, interditando-lhe qualquer acesso ao estatuto de obra. Em vez de ir ao cinema, o espectador radicalmente emancipado de Debord, que precede o de Rancière em mais de meio século, deve, sobretudo, empregar melhor seu tempo na plena ocupação do espaço no mundo vivo. É essa a aposta essencial do projeto debordiano de criação de situações, como a que foi imaginada para a primeira projeção, em Paris, de Hurlements en faveur de Sade (Urros a favor de Sade, Debord, França, 1952, 64 minutos, preto e branco), primeiro filme de Debord, longa metragem sonoro, sem imagens, cuja banda visual é composta apenas pela sucessão de telas brancas e telas pretas, durante 64 minutos. 0 prólogo do filme informa que, antes da projeção, Debord deveria subir no palco e dizer: "não há filme, não pode mais haver; 0 cinema está morto; passemos ao debate, se quiserem". A recusa de imagem é uma forma de impedir a "adição de novas ruínas ao mundo do espectáculo e da lembrança”, como anuncia a banda sonora. Em vez de acrescentar mais um filme aos milhares de filmes existentes, Debord procura, sobretudo, aqui, dar boas razões para não fazê-lo, "substituindo as aventuras fúteis que 0 cinema acumula pelo exame de um tema importante, eu mesmo", como ele diz, em off. Esse "tema importante" não é, evidentemente, nem 0 autor, nem 0 artista ou o cineasta, mas a pessoa, o homem comum em suas atividades cotidianas e insignificantes. Aliás, em todos os seus filmes, Debord e seus amigos aparecem nos momentos de lazer mais banais, bebendo nos bares e perambulando pelas ruas de Paris.

0 primeiro ato situacionista de esquecimento consiste em refutar 0 valor de troca da imagem apropriada e restituir-lhe um valor de uso. Nada de imagens que venham transformar a experiência vivida em informação arquivável, em discurso acabado, em monumento venerável. É nessa perspectiva que se deve compreender sua recusa de imagem, tanto em Hurlements, objeto paradigmático e conceitual, em que 0 método é radicalizado, como nos filmes que virão em seguida, repletos, no entanto, de imagens de arquivo, como La Société du spectacle - A sociedade do espetáculo (1973) - ou In girum imus nocte et consummimur igni -Giramos na noite e somos consumidos pelo fogo (1978). ${ }^{3}$ Mas, nesses dois últimos filmes, a estratégia 
consistirá em desviar o sentido inicial das imagens reutilizadas, a fim de dar-lhes, na montagem, um destino compartilhável, diferente daquele traçado pelas grandes linhas narrativas do espetáculo. A montagem, aqui, acumula imagens, é verdade, mas apoiada numa política de subtração de sentido, de apagamento dos discursos sob os quais elas foram arquivadas. Cada filme de Debord funciona, dessa forma, como um espetáculo a menos. ${ }^{4}$

\section{Desvio}

Hoje, o debate sobre a relação entre cinema e política remete sempre à questão da montagem. Ela reúne o que foi separado. Mas isso, 0 espetáculo também 0 faz. A diferença entre 0 espetáculo e 0 cinema de montagem está na qualidade desta união. "0 espetáculo reúne 0 separado, mas ele o reúne enquanto separado" (DEB0RD, 1992, p. 30). A imagem emblemática dessa separação, na obra de Debord, é a foto publicitária de um casal burguês sorridente, diante de um aparelho de televisão, imagem utilizada no filme $A$ Sociedade do espetáculo e, mais tarde, em In girum. No conforto de seu apartamento moderno, 0 casal transmite 0 sentimento de uma vida plenamente feliz. Mas à cena conjugal, a montagem justapõe imagens de um mundo desolador, que desmentem a felicidade propagada. Às imagens separadas do espetáculo, a montagem atribui um destino histórico comum. A imagem documental do general De Gaulle, discursando, e a imagem publicitária de uma modelo nua na banheira, acariciando um sabonete, aparecem nos cinejornais e na televisão como instantes estritamente separados da vida cotidiana. Colocadas lado a lado, em Sur le passage, elas adquirem uma equivalência e passam a ser percebidas como produto de uma mesma ideologia. A montagem extrai da imagem 0 valor de troca que o espetáculo lhe atribuiu, restituindo-lhe um valor de uso que a torna visível em sua materialidade documental, histórica. Na mesa de montagem de Debord, a imagem de De Gaulle tem o mesmo peso e origem que a da modelo da publicidade. Ambas são documentos susceptíveis de ressignificação por parte do espectador.

0 reemprego de imagens de arquivo no cinema já era praticado desde os anos 1920, pelos construtivistas russos, mas é Debord que revigora essa prática com um método rigoroso, baseado no recurso sistemático à técnica do desvio (détournement). Em francês, como em português, "desviar" (détourner) é tirar uma coisa de um lugar e colocá-la em outro. É também atribuir a uma coisa um movimento circular contrário àquele que lhe foi inicialmente atribuído. Nos aproximamos, aqui, do desvio tal como Debord 
o teorizou, fazendo desse termo o centro de seu projeto estético e político. 0 desvio é, para ele, a ação capaz de mudar o curso dos acontecimentos e de interferir nos rumos da sociedade mercantil.

0 desvio é praticado por Debord desde

Hurlements en faveur de Sade, que mesmo sem imagens, já misturava, de maneira aleatória, sons disparatados (diálogos de filmes de ficção, performances letristas, leituras dos códigos da lei de trânsito...). Os princípios do emprego dessa técnica são sistematizados a partir de 1952 por Guy Debord e Gil Wolman, num texto publicado em maio de 1956, no número 8 da revista Les Lèvres nues, intitulado Mode d'emploi du détournement (Manual de instruções do desvio), uma espécie de tutorial para o desvio de imagens no campo das artes, com fins subversivos. No ambiente de guerra civil posterior à Segunda Guerra Mundial, 0 aparecimento de novas formas produtivas demanda novas relações de produção e novas práticas cotidianas, tendo como consequência, segundo os autores, a obsolescência da arte e 0 fim de seu estatuto de atividade superior. A concepção burguesa do gênio e da arte encontrase ultrapassada e os bigodes da Monalisa já não são mais uma ruptura suficiente. É preciso ir além disso, negar a negação e ultrapassar, inclusive, Brecht, cujos recortes operados nos clássicos do teatro são vistos por Debord e Wolman como intervenções por demais respeitosas para com a cultura, embora úteis e mais próximas do projeto revolucionário dos letristas do que Duchamp, por exemplo (DEBORD; WOLMAN, 1956).

0 manual convida a empregar a herança literária e artística da humanidade em propaganda de guerrilha ou na ação direta, como fizeram em 16 de janeiro de 1963 os estudantes revolucionários de Caracas, ao atacarem à mão armada uma exposição de arte francesa, levando cinco quadros para serem trocados por presos políticos. ${ }^{5}$ Antecipando em mais de meio século alguns aspectos da discussão atual em torno do copyright, Debord e Wolman propõem acabar com a noção de propriedade pessoal em matéria de arte: qualquer elemento, apanhado em qualquer lugar, pode ser objeto de novas aproximações (DEBORD; WOLMAN, 1956). E não basta citar. Para além da citação, o desvio pressupõe uma real interferência nas obras apropriadas, corrigindoas, renovando o que, nelas, estiver ultrapassado. 0 desvio é definido por eles como uma espécie de paródia séria, na qual a acumulação de elementos desviados, longe de querer suscitar a indignação ou o riso, remetendo a uma ideia de obra original, marca, ao contrário, a indiferença em relação a um original vazio de sentido e esquecido.

A teoria do desvio vai ser ainda desenvolvida em outros artigos de Debord e no livro A sociedade do espetáculo. 0 filme homônimo, no qual Debord desloca de seu contexto original imagens distantes umas das outras, justapondo-as, na montagem, em 
corte seco, é a realização prática dessa teoria. Ideia recorrente nas teses eisensteinianas da montagem e retomada no manual de Debord e Wolman, 0 elemento desviado mais longínquo é também aquele que contribui de maneira mais eficaz para dar a impressão de conjunto. Quanto maior o choque dialético entre os elementos justapostos, mais complexa parece ser a relação entre eles.

"0 mundo já foi filmado. Trata-se, agora, de transformá-lo". A frase, considerada um desvio de um pensamento de Marx, para quem o mundo já teria sido pensado e que seria preciso passar à prática, figura numa das cartelas do filme $A$ Sociedade do espetáculo. Ela resume a amplitude política do projeto debordiano: 0 desvio é uma intervenção no presente, concebida para incomodar a ordem existente. Aquilo que o espetáculo tomou da realidade, 0 cinema vai pegar de volta. 0 s expropriadores de imagens serão, por sua vez, expropriados. Debord não quer mais "fazer cinema". Ele quer "fazer uso" do cinema, projetar as imagens do espetáculo "em direção a um estudo do presente como problema histórico" (COPOLLA, 2003, p. 19). 0 desvio permite, assim, a atualização das imagens, seu retorno ao presente. Essa possibilidade de ver de novo e, sobretudo, de ver de outra forma, restituirá, ao espectador, uma experiência do tempo e do espaço.

\section{Pensamento selvagem}

Há uma grande afinidade entre o método situacionista de expropriação das imagens e 0 pensamento selvagem. Aliás, uma das principais publicações dos situacionistas, a revista Potlatch, traz no nome uma referência à forma mais radical de relação econômica entre os homens: 0 potlatch, ritual do dom nas sociedades arcaicas, prevê a destruição total e sacrificatória dos bens materiais, quase sempre através de trocas de presentes. Por meio do dom e do contra-dom, o potlatch tem a função de impedir a acumulação material. 0s homens rivalizam em generosidade, num ritual que toma as proporções de uma grande "festa de comunismo", como 0 potlatch foi definido na antropologia (MAUSS, 1995, p. 149-153). Debord mostrou o abismo existente entre o socialismo histórico (seja ele soviético, chinês ou cubano) e a grande festa de comunismo pagão dos situacionistas. Por meio do desvio, ele criou, na verdade, condições de atualização de gestos humanos ancestrais, num presente desprovido de mistério.

Às vésperas de 1968, esse pensamento crítico incomoda, por sua posição independente e sem concessões. Debord demonstra que o fetichismo da mercadoria não é um apanágio exclusivo do bloco capitalista. Tudo é mercadoria no mundo dominado pelo espetáculo, inclusive a teoria dialética, uma vez que a burocracia estatal dela se apropria. A mercadoria não é somente 0 conjunto dos produtos fabricados pelas mãos do homem, mas também os discursos. A partir do conceito marxiano de fetichismo da mercadoria, centro da produção capitalista, Debord desenvolve sua crítica à sociedade espetacular. Acumulada, a 
mercadoria atinge a abstração da imagem, do discurso: 0 carro último modelo não é mais apenas um automóvel. Sua imagem abstrata interfere nas vendas, no valor de troca, e é assim que a imagem torna-se, ela mesma, uma mercadoria. E como toda mercadoria, a imagem também passa por um processo de acumulação e de desvalorização. Foi assim que o mundo contemporâneo viu-se invadido por um excedente de imagens inúteis.

0 projeto de expropriação e desvio desse excedente tem por objetivo restituir seu justo valor às imagens. Do ponto de vista do conteúdo, os comentários de Debord em seus filmes fazem, principalmente, a crítica do urbanismo e das condições modernas de construção, que consolidam a separação entre os homens. Ele critica, igualmente, o tempo consumível e pseudo-cíclico, em que o homem se ocupa da simples sobrevivência: vivemos numa falsa memória espetacular, que Debord chama de "nãomemorável". É assim que o espetáculo produz uma parilisia da História e uma falsa consciência do tempo. 0 desvio, enquanto método de montagem, tenta reverter essa situação, a priori imutável, reinscrevendo as imagens no curso da história e da vida.

Um breve trecho do filme $A$ Sociedade do espetáculo mostra como a montagem pode subverter as verdades estáticas da História. No final da primeira parte, o comentário de Debord se interrompe, dando lugar ao diálogo silencioso entre um documento histórico, a fotografia do líder anarquista espanhol Buenaventura Durruti, e uma imagem de ficção, o plano do rosto de um marinheiro do Encouraçado Potemkin, de Eisenstein (1925). Assistimos à aproximação inesperada de duas imagens distantes uma da outra no tempo e no espaço, dificilmente agrupáveis se não fosse a adoção de um estilo de montagem moderno, em ruptura com a continuidade narrativa da grande História. De um lado, a guerra da Espanha, evocada pela foto de Durruti, e do outro lado, a revolução russa, evocada pelo filme de Eisenstein. Depois da foto de Durruti, segue-se uma cartela, com a pergunta: "Isso é vida, proletários, isso é vida?" A resposta é dada pelo movimento negativo de cabeça do marinheiro do Encouraçado. A foto de Durruti fala por intermédio das cartelas, num desvio bastante simples, que possibilita o encontro de diferentes tempos históricos: na pergunta dirigida ao marinheiro russo, Durruti, testemunha importante de um passado de resistência, emite, na verdade, uma crítica ao stalinismo do presente. Uma mesma abordagem associativa de imagens distantes umas das outras aparecerá, mais tarde, nas História(s) do cinema, de Godard (1988-1998).

0 desvio das imagens torna o passado novamente possível. Agamben falará da técnica de composição de Debord como um método que extrai da montagem sua dupla potência de interrupção e repetição (AGAMBEN, 1998). Após meia hora de filme, marcada por um fluxo ininterrupto de imagens, o diálogo entre Durruti e o marinheiro oferece ao espectador uma primeira pausa. A 
acumulação de imagens à qual o filme faz alusão é interrompida e a montagem permite uma outra leitura das imagens mostradas. Ao dialogar com um documento da guerra civil espanhola, o marinheiro de Eisenstein sai da ficção e entra na história, numa crítica sutil à União Soviética de então.

0 vivo foi transformado em coisa consumível e o homem viu-se privado de suas referências elementares de tempo e espaço. 0 desvio inverte esta situação, por meio de um duplo movimento: primeiro, ele interrompe o processo de reificaçao do vivo, extraindo a imagem reempregada do sistema de troca e desvinculando-a do discurso de arquivamento; ele "desvaloriza", assim, a representação original, como diz Antoine Coppola. Em seguida, a montagem atualiza essas mesmas imagens, associandoas a um pensamento crítico que impede a representação de nelas se reinscrever. É a função do comentário de Debord, um comentário que resiste à informação, como viu Agamben.

As imagens do espetáculo voltam-se contra si mesmas, produzindo contra-informação. Debord definiu Hurlements en faveur de Sade como um empreendimento para um terrorismo cinematográfico. Todos os seus filmes atacam 0 sistema de informação clássico. A banda sonora e a banda visual elaboram racicíonios em looping e é com essa história em aspiral que o resgate das imagens operado por ele desencadeia um tipo de revolução cósmica, que restitui ao espectador a possibilidade de se relacionar com o tempo e com 0 espaço.

\section{Desvios contemporâneos}

Meio século depois, Eduardo Coutinho faz um filme, sob vários aspectos, situacionista, retomando a técnica do desvio e avançando em relação à montagem de Debord. A partir de 19 horas de registro ininterrupto da programação de diferentes canais abertos da televisão brasileira, Coutinho montou um filme de uma hora e meia de duração, com trechos de diferentes programas. Um dia na vida (2011) não interfere na edição interna desses programas e 0 cineasta se limita a produzir cortes na duração dos mesmos. Ao contrário dos filmes de Debord, Coutinho não emite, aqui, nenhum comentário. Nada é acrescentado ao material gravado, nenhuma explicação do projeto, nenhuma entrevista analítica do fato televisivo, nenhuma inscrição gráfica. Duas únicas cartelas abrem o filme: uma com o título e o subtítulo (Um dia na vida. Projeto para um filme futuro) e outra informando que 0 material foi gravado em $1^{\circ}$ de outubro de 2009, nas televisões Brasil, SBT, Globo, Bandeirantes, Record e MTV. Não há ficha técnica reivindicando a autoria do gesto e esse objeto, inclassificável e anônimo, se limita a expor a estética da televisão de maneira direta, como matéria a ser apropriada por outros, num "filme futuro". Por razões legais, relacionadas ao controle do direito de imagem por parte das televisões, o filme não pode ser distribuído e tem sido projetado na presença do cineasta, que aparece no final das sessões para debater com o público. 
0 filme é composto unicamente de imagens da televisão. Os blocos se encadeiam sem nenhum comentário e a televisão nos é entregue praticamente em estado bruto, mas num formato de cinema, ou seja, projetável. 0 filme tira a televisão de seus espaços habituais de difusão e da tela pequena, lugares da atenção dispersa, trazendo-a para a sala escura de cinema, lugar da atenção supostamente concentrada. Embora esteja mais próxima de um manifesto do que de um filme, essa montagem coloca uma diferença fundamental, em termos espaciais e temporais, entre cinema e televisão, entre projeção e difusão. 0 cinema é a maior de todas as artes, porque ele se projeta, dizia Godard em suas História(s) do cinema. Projetar uma imagem é lançá-la num espaço delimitado, tendo como alvo um espectador singular, com quem a imagem projetada estabelece uma relação de alteridade, dele solicitando o reconhecimento capaz de inscrevê-la no curso da história. Difundir uma imagem, ao contrário, é propagá-la num espaço impreciso, tendo como alvo um público genérico, igualmente difuso, com 0 qual a imagem assim difundida estabelece uma relação de poder, que 0 absorve num eterno presente, sem passado e sem futuro, sem história. Cinema e televisão ocupam diferentemente 0 espaço e, por isso, o tempo resultante dessa ocupação é também diferenciado.

Um dia na vida cristaliza as imagens liquefeitas da televisão, na medida em que sua montagem cria a possibilidade de projeção para algo até então destinado a desaparecer na difusão. E ao fazer isso, o filme desnaturaliza essa televisão que tornou-se um fim em si mesma e que se reproduz de maneira tautológica em cada uma de suas imagens, ao ponto de confundir-se com a imagem de um país inteiro. À omnipresença da tevê nos espaços públicos e privados no Brasil, soma-se uma política de banalização do horror, apresentado como parte integrante da paisagem, uma fatalidade cultural, um componente ontológico da própria vida em sociedade. Colocada à prova da tela grande do cinema e da duração obrigatória de uma hora e meia de projeção, diante de um espectador, a princípio, atento, a imagem da televisão passa a produzir um estranhamento: 0 horror, agora, perturba, suscitando no espectador a análise do discurso que o produz e a avaliação de seus efeitos.

\section{0 que vemos?}

A montagem de Um dia na vida é um exercício de democracia, que coloca em pé de igualdade todos os programas desviados. Se antes, na recepção dispersa da tela pequena, víamos apenas um fluxo contínuo, agora temos tempo para estudar as imagens e comparar os diferentes canais. Em vez de desligar o aparelho ou mudar de canal, como faríamos em casa, nossa atenção se engaja numa atividade associativa de imagens que, embora ligeiramente diferentes umas das outras, compõem um mesmo objeto, o filme.

De um canal de televisão a outro, sem transição, somos submetidos a um encadeamento 
de assuntos sem nexo, como os sons de

Hurlements: sexo, deus, criança, polícia, traficante, cirurgia plástica, atropelamento, guerra, moda... Dezenas de programas apresentados pela tevê como quadros separados da sociedade brasileira, são reunidos por Coutinho em três categorias: "programas de bundas, de pastores e de pedofilia", compreendendo, esse último gênero, a massa de publicidade com crianças e para crianças. ${ }^{6}$ 0 filme nos coloca diante de um mundo que nos escapa e do qual gostaríamos de escapar. Mas na medida em que a projeção avança e que resistimos ao desejo inicial de deixar a sala, percebemos uma lógica interna que rege essas imagens violentas. 0 fluxo incompreensível, agora retido, se condensa numa única imagem, monstruosa, de uma sociedade despolitizada, infantilizada, violentada. Como no desvio debordiano, a montagem de Um dia na vida reúne o que o espetáculo separou, criando a possibilidade de uma visão de conjunto.

A violência que a televisão apresenta como manifestação supostamente atávica e factual de uma pequena parcela de pessoas inadaptadas, a serem extirpadas do corpo social, aparece agora em cada uma das imagens que a montagem de Um dia na vida associa umas às outras. Durante o filme, ouvimos, indistintamente, jornalistas e pastores pronunciarem 11 vezes as palavras "bandido", "criminoso" e "vagabundo", para se referirem a homens infratores. A

condensação de canais e programas expõe a própria gestação do discurso da violência. Desse grande desvio das imagens da televisão brasileira, a violência emerge num só bloco, em sua dimensão arcaica, de classe, trazendo à tona um projeto de extermínio que remonta a um processo colonizatório ainda em expansão, agora sob a égide do evangelismo e do telejornalismo.

Exposto enquanto tal, o fluxo de imagens, concebido para que delas nos esqueçamos rápido, torna-se tangível, memoriável. Embora o filme contenha trechos da programação de vários canais, em diferentes horas do dia, incluindo publicidade, telejornais, novelas, desenho animado e todo tipo de programa de auditório, a estética que se descola desse material bruto é homogênea, como se $U m$ dia na vida tivesse retido a imagem das imagens da televisão, numa única e longa sequência de 90 minutos de duração. Um dia na vida permite ver a televisão demoradamente e, assim, proceder a uma decomposição analítica dos discursos fascistas que, aos berros, ela transforma em natureza. Nisso reside a pedagogia exemplar da técnica do desvio, tal como Coutinho a desenvolve: ele interrompe e repete as imagens da televisão, impõe um limite espaço-temporal a sua liquefação de sentido e cria rugosidades que permitem a aderência do 
olhar do espectador numa superfície antes lisa e não problemática.

\section{Coutinho situacionista}

0 recorte que Um dia na vida faz no fluxo da televisão retira as imagens de seu curso natural e a montagem restaura 0 fato televisivo total, ou seja, a televisão mais os discursos que a produzem e que ela, habilmente, dissimula no encadeamento ininterrupto e objetivante de sua programação. A montagem de Coutinho e Jordana Berg torna nossos ouvidos mais sensíveis à gritaria reinante. 0 filme nos restitui a experiência da primeira vez que vimos televisão, sem a inocência da primeira vez.

Esse tipo de acontecimento, que favorece a experiência viva, tão cara aos situacionistas, foi chamado, na antropologia, de "fato social total" (MAUSS, 1995). Num texto fundador, do início do século XX, Mauss convidava a antropologia nascente a recompor o todo da vida em sociedade, religando o social e 0 individual, o físico e o psíquico, mostrando que 0 fato social se encarna, ao mesmo tempo, numa experiência individual, que é a história de cada um. 0 fato social total reintegra os aspectos descontínuos da vida (familiar, técnico, econômico, jurídico, religioso), produzindo seres totais, indivisíveis.
0 observador social, sendo da mesma natureza que seu objeto, passa a fazer parte da observação (MAUSS, 1995). A montagem de Coutinho se apoia nessas mesmas bases antropológicas, que sustentaram o projeto situacionista. Assim como Debord, que entre os anos 1950 e 1970 se aplicou em tomar as imagens do espetáculo para devolvêlas à sociedade, Coutinho também faz uma obra de estrategista. Um dia na vida desnaturaliza o naturalizado, ocupa o ocupante, expropria 0 expropriador, trazendo a televisão de volta para 0 espaço social, como um objeto, enfim, apropriável. Seu filme politiza as imagens da televisão e torna, finalmente, público, um espaço ilicitamente privatizado. Um dia na vida é um filme-manifesto, próximo, em termos políticos, de Hurlements en faveur de Sade, filme que só tem sentido se for apropriado pelo espectador. ${ }^{7}$

A separação que a tevê alimenta cria 0 homem indignado e ressentido. Como diz Agamben (1998, p. 71), "as mídias nos dão sempre o fato, o que aconteceu, sem a sua possibilidade, sem a sua potência; elas nos dão um fato em relação ao qual somos impotentes". Daí a nossa indignação. No senso comum, "indignado" quer dizer "revoltado". Mas no sentido etimológico, o indignado é aquele que não tem dignidade. Como reestabelecer para o espectador "uma dignidade do ser"? É a grande questão de Comolli, que vê no documentário a 
última forma de afrontar a "espetacularização crescente das sociedades humanas" e sua produção de cidadãos impotentes (COMOLLI, 2004, p. 22). Não era outra a preocupação de Debord, já nos anos 1950, ao propor aplicações permormáticas e arquivísticas das técnicas de reprodução das imagens, como estratégia de ação política:

Podemos conceber, por exemplo, uma televisão projetando, ao vivo, alguns aspectos de uma situação numa outra situação, desencadeando, assim, modificações e interferências. Mas, mais simplesmente, 0 cinema dito de atualidades poderia começar a merecer o seu nome, formando uma nova escola de documentário, que registrasse, para os arquivos situacionistas, os instantes mais significativos de uma situação (DEBORD, 1997, p. 40-41, tradução nossa).

Arquivo e performance, dois focos de interesse do cinema contemporâneo, presentes na obra de Debord desde seu primeiro filme e que participam, igualmente, do projeto de montagem de Um dia na vida. Além de remontar programas de televisão, 0 filme de Coutinho instala 0 espectador numa situação que exige dele uma intervenção no presente. A montagem de Coutinho é silenciosa e convoca a inteligência do espectador. Durante as projeções há sempre muita conversa entre os espectadores e a plateia funciona como um contraplano vivo do filme. Ao término da projeção, 0 diálogo se instala entre 0 cineasta e seu público, suscitando uma crítica da televisão tão contundente quanto os melhores manifestos situacionistas. Debord não poderia imaginar situação mais eficaz provocada pelo cinema.

A crítica que, tradicionalmente, se faz a Debord, refere-se, via de regra, ao caráter discursivo de seus filmes. No entanto, trata-se de uma obra narrada na primeira pessoa, por um montador que se posiciona enquanto espectador das imagens do espetáculo. Se há discurso, é sobre a própria relação do montador com as imagens. 0 objetivo não é impor um discurso ou constituir uma obra, mas desencadear, com 0 cinema, ações comuns e sem autoria. Nada de mais recorrente do que esse tipo de proposta no âmbito das produções artísticas contemporâneas. Rancière viu, no entanto, na crítica do espetáculo de Debord mais uma reformulação anacrônica da oposição platônica entre choreía (performance dos corpos) e teatro (simulacro do espetáculo). 0 espectador de Debord refutaria, segundo Rancière, qualquer interação com 0 espetáculo: "a contemplação que Debord denuncia é a contemplação da aparência separada de sua verdade" (RANCIERE, 2008, p. 13, tradução nossa). E, para Rancière, os dispositivos contemporâneos uniriam de tal forma imagem e realidade viva, público teatral e comunidade, que a crítica da separação ou do espectador passivo não teria mais, hoje, razão de ser. No mundo de espectadores emancipados de Rancière não haveria mais passividade do olhar? Não haveria mais imagem ou cena separada da vida que justificasse nossa indignação? 
Se retornamos aos textos de Debord - o que Rancière, curiosamente, não faz - verificamos que esse espectador capaz de apropriar-se criticamente das imagens existentes e de produzir suas próprias imagens já era o centro do debate situacionista. Mas esse espectador, foi preciso inventá-lo. A relação de Debord com as imagens participa dessa invenção. Seria um erro vincular o projeto debordiano a uma tradição platônica que diminuiria o poeta face ao filósofo. Debord via nas imagens uma positividade inequívoca, a partir do momento em que o espectador delas se apropria. Elas devem funcionar como um ponto de encontro, um mero pretexto para se criar situações e por isso não devem ser feitas para durar. "Nossas situações serão sem futuro, serão lugares de passagem. 0 caráter imutável da arte, ou de qualquer outra coisa, não entra em nossas considerações, que são sérias. A ideia de eternidade é a mais grosseira que um homem possa conceber a propósito de seus atos" (DEBORD, 2000, p. 40).

Na obra de Debord, a desmistificação da arte e a crítica da alienação não implicam numa negatividade da imagem nem a relegam aos bastidores do discurso. 0 objetivo da atividade artística, para ele, era integrar as imagens à vida. E, nesse sentido, a técnica do desvio inaugurava, já nos anos 1950, sua "comunidade de iguais" (RANCIERE, 1987). 0 projeto situacionista não separa estética e política e o pensamento debordiano sobre as imagens não parece se alinhar a um regime ético platônico, separado do regime poético, como pretende Rancière (2000). Para o situacionismo, nunca houve distinção entre ação política e poética do cotidiano.

Hoje, nos espaços brasileiros, marcados pela ocupação consensual da televisão, desligar um aparelho de transmissão pode ser considerado um gesto ofensivo e quem ousa fazê-lo corre o risco de passar por um excêntrico. Coutinho ousou: Um dia na vida, filme sem autor, é a história de um homem que desligou a televisão e foi ao cinema, debater com o espectador. Debord também ousou, com outras táticas, que respondiam às necessidades do seu tempo. Hurlements en faveur de Sade tirou o espectador das salas de cinema e foi com ele para as ruas, preparar maio de 68. Resta saber qual vai ser a reação do telespectador brasileiro de hoje, diante de Um dia na vida. Desligar, provisoriamente, a televisão, para repensá-la? Já seria um bom começo.

\section{Referências}

AGAMBEN, Giorgio. Le cinéma de Guy Debord. Image et mémoire. Hoëbeke, 1998.

COMOLLI, Jean-Louis. Ver e poder. Lagrasse: Verdier, 2004 .

COPOLLA, Antoine. Introduction au cinéma de Guy Debord et de l'avant-garde situationniste. Arles: Sulliver, 2003.

DEBORD, Guy. Rapport sur la construction des situations. Paris: Mille et une nuits, 2000.

DEBORD, Guy. La société du spectacle. Paris: Editions Gallimard, 1992.

DEBORD, Guy; JORN, Asger. Mémoires. Copenhague : 
Internationale situationniste, 1959.

DEBORD, Guy; WOLMAN, Gil. Mode d'emploi du détournement. Les Lèvres nues, Bruxelas, n. 8, maio, p. 6, 1956.

DERRIDA, Jacques. Surtout pas de journalistes! Paris: L’Herne, 2005.

ENCOURAÇADO Potemkin. Direção: Eisenstein. Rússia, 1925, $74 \mathrm{~min}$.

GUIMARÃES, César. Um dia na vida do outro espectador. Devires. Belo Horizonte, v. 7, n. 2, p. 140149, jul./dez. 2010.

HISTÓRIA(S) do cinema. Direção: Jean Luc Godard. França, 1988-1998, 266 min. color.

IN GIRUM imus nocte et consummimur igni. Direção: Guy Debord. França, 1978, 95 min.

LEANDR0, Anita. Politiques du montage chez Guy Debord. In: BOLTER, Trudy (Org.). Expressions du politique au cinema. Bordeaux: Pleine page, 2006.

LINS, Consuelo. Do espectador crítico ao espectadormontador. Devires. Belo Horizonte, v. 7, n. 2, p. 132138, jul./dez. 2010.

MAUSS, Marcel. Essai sur le don. Forme et Raison de l'échange dans les sociétés archaïques. In: MAUSS, Marcel. Sociologie et anthropologie. Paris: PUF, 1995.

RANCIERE, Jacques. Le maître ignorant. Paris: Fayard, 1987.

RANCIERE, Jacques. Le partage du sensible. Paris: La Fabrique, 2000.

RANCIERE, Jacques. Le spectateur émancipé. Paris: La Fabrique, 2008.

LA SOCIÉTÉ du spectacle. Direção: Guy Debord. França, 1973, 88 min.

SUR LE PASSAGE de quelques personnes à travers une assez courte unité de temps. Direção: Guy Debord. França, 1959, 20 min.
TURISMO Vândalo. Direção: Gianikian e Ricci Lucci. França, 2001, 62 min., color.

UM DIA na vida. Direção: Eduardo Coutinho. Brasil, 2011, 90 min. color.

VIDEOGRAMAS de uma revolução. Direção: Harun Farocki e Andrei Ujica. Alemanha, 1991-1992, 107 min. color. 


\begin{tabular}{|c|c|}
\hline Images detournements & Desvíos de imagenes \\
\hline $\begin{array}{l}\text { Abstract } \\
\text { Detourne existing images from its original function } \\
\text { and use them in a new context, in a way to amplify } \\
\text { the political meaning of the montage and to transform } \\
\text { the cinema in a place of exchange of experiences: } \\
\text { that was Guy Debord's project, taken again now, } \\
\text { under new basis, by directors who work with archives } \\
\text { images. This article analyses the detournment } \\
\text { throught Debord films and writings and evaluates } \\
\text { how up to date is the situacionist proposal. } \\
\text { Keywords } \\
\text { Debord. Coutinho. Détournement. }\end{array}$ & $\begin{array}{l}\text { Resumen } \\
\text { Desviar de su funccion originaria imagenes } \\
\text { existentes y actualizarlas en un nuevo contexto para } \\
\text { resforzar el alcance politico del gesto del montaje, } \\
\text { y transformar el cine en un lugar de intercambio } \\
\text { de experiencias. Esa era la esencia del proyecto de } \\
\text { Guy Debord, retomado, hoy dia, sobre nuevas bases, } \\
\text { por cineastas que trabajan con imagenes de archivo. } \\
\text { Uilizaremos las peliculas y los textos de Debord para } \\
\text { analizar la tecnica de la "distorsion" y evaluar la } \\
\text { actualidad de la propuesta situacionista. } \\
\text { Palabras claves }\end{array}$ \\
\hline
\end{tabular}




\section{Expediente}

A revista E-Compós é a publicação científica em formato eletrônico da Associação Nacional dos Programas de Pós-Graduação em Comunicação (Compós). Lançada em 2004, tem como principal finalidade difundir a produção acadêmica de pesquisadores da área de Comunicação, inseridos em instituições do Brasil e do exterior.
E-COMPÓS I www.e-compos.org.br I E-ISSN 1808-2599

Revista da Associação Nacional dos Programas

de Pós-Graduação em Comunicação.

Brasília, v.15, n.1, jan./abr. 2012.

A identificação das edições, a partir de 2008

passa a ser volume anual com três números.

\section{CONSELHO EDITORIAL}

Afonso Albuquerque, Universidade Federal Fluminense, Brasil Alberto Carlos Augusto Klein, Universidade Estadual de Londrina, Brasil Álvaro Larangeira, Universidade Tuiuti do Paraná, Brasil Ana Carolina Damboriarena Escosteguy, Pontifícia Universidade Católica do Rio Grande do Sul, Brasil

Ana Gruszynski, Universidade Federal do Rio Grande do Sul, Brasil Ana Silvia Lopes Davi Médola, Universidade Estadual Paulista, Brasil André Luiz Martins Lemos, Universidade Federal da Bahia, Brasil Ângela Freire Prysthon, Universidade Federal de Pernambuco, Brasil Angela Cristina Salgueiro Marques, Faculdade Cásper Líbero (São Paulo), Brasil Antônio Fausto Neto, Universidade do Vale do Rio dos Sinos, Brasil Antonio Carlos Hohlfeldt, Pontifícia Universidade Católica do Rio Grande do Sul, Brasil Antonio Roberto Chiachiri Filho, Faculdade Cásper Líbero, Brasil Arthur Autran Franco de Sá Neto, Universidade Federal de São Carlos, Brasil Benjamim Picado, Universidade Federal Fluminense, Brasil César Geraldo Guimarães, Universidade Federal de Minas Gerais, Brasil Cristiane Freitas Gutfreind, Pontifícia Universidade Católica do Rio Grande do Sul, Brasil Denilson Lopes, Universidade Federal do Rio de Janeiro, Brasil Eduardo Peñuela Cañizal, Universidade Paulista, Brasil Eduardo Vicente, Universidade de São Paulo, Brasil Eneus Trindade, Universidade de São Paulo, Brasil Erick Felinto de Oliveira, Universidade do Estado do Rio de Janeiro, Brasil Florence Dravet, Universidade Católica de Brasilia, Brasil Gelson Santana, Universidade Anhembi/Morumbi, Brasil Gislene da Silva, Universidade Federal de Santa Catarina, Brasil Guillermo Orozco Gómez, Universidad de Guadalajara Gustavo Daudt Fischer, Universidade do Vale do Rio dos Sinos, Brasil Hector Ospina, Universidad de Manizales, Colômbia Herom Vargas, Universidade Municipal de São Caetano do Sul, Brasil leda Tucherman, Universidade Federal do Rio de Janeiro, Brasil Inês Vitorino, Universidade Federal do Ceará, Brasil Jnice Caiafa, Universidade Federal do Rio de Janeiro, Brasil Jay David Bolter, Georgia Institute of Technology Jeder Silveira Janotti Junior, Universidade Federal de Pernambuco, Brasil João Freire Filho, Universidade Federal do Rio de Janeiro, Brasil John DH Downing, University of Texas at Austin, Estados Unidos José Afonso da Silva Junior, Universidade Federal de Pernambuco, Brasil
José Carlos Rodrigues, Pontifícia Universidade Católica do Rio de Janeiro, Brasil José Luiz Aidar Prado, Pontifícia Universidade Católica de São Paulo, Brasil José Luiz Warren Jardim Gomes Braga, Universidade do Vale do Rio dos Sinos, Brasil Juremir Machado da Silva, Pontifícia Universidade Católica do Rio Grande do Sul, Brasil Laan Mendes Barros, Universidade Metodista de São Paulo, Brasil Lance Strate, Fordham University, USA, Estados Unidos Lorraine Leu, University of Bristol, Grã-Bretanha Lucia Leão, Pontifícia Universidade Católica de São Paulo, Brasil Malena Segura Contrera, Universidade Paulista, Brasil Márcio de Vasconcellos Serelle, Pontifícia Universidade Católica de Minas Gerais, Brasil Maria Aparecida Baccega, Universidade de São Paulo e Escola Superior de Propaganda e Marketing, Brasil Maria das Graças Pinto Coelho, Universidade Federal do Rio Grande do Norte, Brasil Maria Immacolata Vassallo de Lopes, Universidade de São Paulo, Brasil Maria Luiza Martins de Mendonça, Universidade Federal de Goiás, Brasil Mauro de Souza Ventura, Universidade Estadual Paulista, Brasil Mauro Pereira Porto, Tulane University, Estados Unidos Mirna Feitoza Pereira, Universidade Federal do Amazonas, Brasil Nilda Aparecida Jacks, Universidade Federal do Rio Grande do Sul, Brasil Paulo Roberto Gibaldi Vaz, Universidade Federal do Rio de Janeiro, Brasil Potiguara Mendes Silveira Jr, Universidade Federal de Juiz de Fora, Brasil Renato Cordeiro Gomes, Pontifícia Universidade Católica do Rio de Janeiro, Brasil Robert K Logan, University of Toronto, Canadá

Ronaldo George Helal, Universidade do Estado do Rio de Janeiro, Brasil Rose Melo Rocha, Escola Superior de Propaganda e Marketing, Brasil Rossana Reguillo, Instituto de Estudos Superiores do Ocidente, Mexico Rousiley Celi Moreira Maia, Universidade Federal de Minas Gerais, Brasil Sebastião Carlos de Morais Squirra, Universidade Metodista de São Paulo, Brasil Sebastião Guilherme Albano da Costa, Universidade Federal do Rio Grande do Norte, Brasil

Simone Maria Andrade Pereira de Sá, Universidade Federal Fluminense, Brasil Tiago Quiroga Fausto Neto, Universidade de Brasília, Brasil

Suzete Venturelli, Universidade de Brasilia, Brasil Valério Cruz Brittos, Universidade do Vale do Rio dos Sinos, Brasil Valerio Fuenzalida Fernández, Puc-Chile, Chile Veneza Mayora Ronsini, Universidade Federal de Santa Maria, Brasil Vera Regina Veiga França, Universidade Federal de Minas Gerais, Brasil

\section{COMISSÃO EDITORIAL}

Adriana Braga I Pontifícia Universidade Católica do Rio de Janeiro, Brasil

Felipe Costa Trotta I Universidade Federal Fluminense, Brasil

CONSULTORES AD HOC

Bruno Campanella, Universidade Federal Fluminense, Brasil

Gisela Grangeiro da Silva Castro, Escola Superior de Propaganda e Marketing, Brasi José Carlos Ribeiro, Universidade Federal da Bahia, Brasil

Luciana Panke, Universidade Federal do Paraná, Brasil

Micael Herschmann, Universidade Federal do Rio de Janeiro, Brasil

Tânia Márcia Cezar Hoff, Escola Superior de Propaganda e Marketing, Brasil

Virginia da Silveira Fonseca, Universidade Federal do Rio Grande do Sul, Brasil

EDIÇÃO DE TEXTO E RESUMOS I Susane Barros

SECRETÁRIA EXECUTIVA I Juliana Depiné

EDITORAÇÃo ELETRÔNICA I Roka Estúdio
COMPós I www.compos.org.br

Associação Nacional dos Programas de Pós-Graduação em Comunicação

Presidente

Julio Pinto

Pontifícia Universidade Católica de Minas Gerais, Brasil

juliopinto@pucminas.br

Vice-presidente

Itania Maria Mota Gomes

Universidade Federal da Bahia, Brasil

itania@ufba.br

Secretária-Geral

Inês Vitorino

Universidade Federal do Ceará, Brasil

inesvict@gmail.com 